\title{
Angiotensin Induces the Urinary Peristaltic Machinery during the Perinatal Period
}

\author{
Yoichi Miyazaki, ${ }^{*}$ Shinya Tsuchida, ${ }^{\star}$ Hideki Nishimura, ${ }^{\star}$ John C. Pope, IV, ${ }^{\ddagger}$ Raymond C. Harris, ${ }^{\S}$ James M. McKanna," \\ Tadashi Inagami," Brigid L.M. Hogan, ${ }^{\| \star \star}$ Agnes Fogo, ${ }^{\star \ddagger \ddagger}$ and lekuni Ichikawa ${ }^{\star \S}$ \\ *Department of Pediatrics, ${ }^{*}$ Department of Urology, ${ }^{\S}$ Department of Medicine, ${ }^{* D e p a r t m e n t ~ o f ~ C e l l ~ B i o l o g y, ~}{ }^{\mathbb{} D e p a r t m e n t ~ o f ~}$ \\ Biochemistry, **Howard Hughes Medical Institute, and ${ }^{\ddagger}$ Department of Pathology, Vanderbilt University Medical Center, Nashville, \\ Tennessee 37232
}

\begin{abstract}
The embryonic development of mammalian kidneys is completed during the perinatal period with a dramatic increase in urine production, as the burden of eliminating nitrogenous metabolic waste shifts from the placenta to the kidney. This urine is normally removed by peristaltic contraction of the renal pelvis, a smooth muscle structure unique to placental mammals. Mutant mice completely lacking angiotensin type 1 receptor genes do not develop a renal pelvis, resulting in the buildup of urine and progressive kidney damage. In mutants the ureteral smooth muscle layer is hypoplastic and lacks peristaltic movements. We show that angiotensin can induce the ureteral smooth muscles in organ cultures of wild-type, but not mutant, ureteral tissues and that, in wild-type mice, expression of both renal angiotensin and the receptor are transiently upregulated at the renal outlet at birth. These results reveal a new role for angiotensin in the unique cellular adaptations of the mammalian kidney to the physiological stresses of postnatal life. $(J$. Clin. Invest. 1998. 102:1489-1497.) Key words: gene targeting • angiotensin type 1 receptor • renal pelvis - ureter • hydronephrosis
\end{abstract}

\section{Introduction}

Multiple physiological adaptations must occur in placental mammals at birth when the fetus switches from dependence on a maternal life support system to a free living existence. The renal system, in particular, faces multiple challenges at this time. As the only ex utero mechanism for the removal of nitrogenous waste, the kidney achieves some 50-fold increase in urine production during the perinatal period (1). At the same time, the urine must be efficiently removed from the kidney to prevent the buildup of intrarenal pressure. The latter task is accomplished by the development of the pelvis, an organ unique to mammals. Under the control of its pacemaker cells $(2,3)$, the pelvis initiates peristaltic movements to rapidly transfer urine from the kidney to the downstream ureter. Here, we provide evidence that angiotensin controls the neo-

Address correspondence to Iekuni Ichikawa, M.D., Ph.D., Vanderbilt University Medical Center, MCN C4204, 21st and Garland Avenue, Nashville, TN 37232-2584. Phone: 615-322-7931 or 7416; FAX: 615322-7929; E-mail: iekuni.ichikawa@mcmail.vanderbilt.edu

Received for publication 25 June 1998 and accepted in revised form 18 August 1998.

J. Clin. Invest.

(C) The American Society for Clinical Investigation, Inc. 0021-9738/98/10/1489/09 \$2.00

Volume 102, Number 8, October 1998, 1489-1497

http://www.jci.org natal development of the kidney outflow tract by inducing the development of the pelvis and by stimulating the proliferation and differentiation of smooth muscle cells around the ureter. In mice in which both angiotensin 1 receptor (AT1) ${ }^{1}$ genes have been completely inactivated, the renal pelvis fails to develop, the number of smooth muscle cells in the ureter increases poorly, and no peristaltic movement can be measured. Consequently, by 3 wk of age, irreversible kidney damage occurs.

\section{Methods}

Animals studied. To obtain pups and embryos lacking genes encoding both AT1A and AT1B receptors, double heterozygous null mutants (Agtr1a $+/-$; Agtr1b $+/-)$ on a mixed 129/Ola and C57BL/6 genetic background were interbred as described previously (4) to produce offspring that carry the genotype $+/+$ or Agtrla $-/-$; Agtr1b -1- (abbreviated as Agtr1 -/-). Agtr1 genotype was determined by Southern blot analysis on DNA isolated from tail biopsies or yolk sac. Angiotensinogen null mutant mice $(A g t-/-)$ were obtained as described previously (5).

Preparation of wild-type mice undergoing surgical unilateral ureteral obstruction. Under anesthesia by intraperitoneal injection of sodium pentobarbital ( $60 \mathrm{mg} / \mathrm{kg}$ body wt), left ureters of 16-d-old wildtype mice $(n=6)$ were ligated with 6-0 silk and cut between the two ligated points, while in sham operation $(n=6)$, the ureter was identified and left undisturbed. After the pups were recovered from anesthesia, they were returned to their mother. At $5 \mathrm{~d}$ after surgery, obstructed kidneys were harvested and subjected to the TUNEL method.

Assessment of renal pelvic and ureteral peristaltic function. Mice were anesthetized with an intraperitoneal injection of $60 \mathrm{mg} / \mathrm{kg}$ body wt sodium pentobarbital. After tracheostomy, a polyethylene catheter (PE-10) was placed into the right jugular vein for continuous infusion of saline at the rate of $2 \mathrm{ml} / \mathrm{h}$. After a midline incision of abdomen, the dome of the bladder was punctured with a $22-\mathrm{G}$ needle to allow free urine outflow. The fat pad surrounding the kidney was anchored in order to immobilize the left renal pelvis. Fat pads surrounding the pelvis were gently removed. The intrapelvic pressure was recorded with a continuous recording, servonull micropipette transducer system (model 4A; Instrumentation for Physiology and Medicine, San Diego, CA), as described previously (6).

In vivo tissue morphology. At least four animals of each genotype were analyzed for each specific developmental stage. Tissue slices were fixed in $4 \%$ buffered paraformaldehyde, routinely processed, embedded in paraffin, and sectioned at $4 \mu \mathrm{m}$. For frozen sections, tissue slices were placed in O.C.T. compound (Sakura, Tokyo, Japan), and immediately frozen in absolute ethanol containing dry ice. Sections were then cut $(10 \mu \mathrm{m})$ at $-20^{\circ} \mathrm{C}$, and thaw-mounted on glass slides. The sections were routinely stained with periodic acid

1. Abbreviations used in this paper: Agtr1 -/-, homozygote for null mutations in both the angiotensin type $1 \mathrm{~A}$ and $1 \mathrm{~B}$ receptor genes; Ang II, angiotensin II; AT1, angiotensin 1 receptor; BrdU, bromodeoxyuridine; SMA, smooth muscle actin. 
Schiff and hematoxylin and eosin for qualitative and quantitative analyses.

Analyses for cell proliferation and cell death. $1 \mathrm{~d}$ before killing, mice were given three intraperitoneal injections of bromodeoxyuridine (BrdU; $0.1 \mathrm{mg} / \mathrm{g}$ body wt; Boehringer Mannheim, Mannheim, Germany) at 8-h intervals. $2 \mathrm{~h}$ after the last injection, kidneys and ureters were removed and processed as described above. Immunostaining for BrdU was performed with anti-BrdU antibody (CALBIOCHEM, Cambridge, MA) following the manufacturer's protocol. Three nonadjacent sections from the root portion of pelvis were collected, and the percentage of BrdU positive nuclei against total nuclei was determined for the smooth muscle layer. The TUNEL method was used to detect apoptotic cells as described by Gavrieli et al. (7).

$\left[\right.$ Sar $^{1}$, Ile $\left.^{8}\right]$ Angiotensin II receptor autoradiography. The distribution of angiotensin II (Ang II) receptors was assessed by the in situ autoradiographic technique of Ciuffo et al. (8). After preincubation, frozen sections were incubated with $0.5 \mathrm{nM}^{125} \mathrm{I}-\left[\mathrm{Sar}^{1}, \mathrm{Ile}^{8}\right]$ Ang II and $3 \mu \mathrm{M}$ of PD123319 in the presence or absence of $3 \mu \mathrm{M}$ losartan. After fixation of the sections with formaldehyde vapor in a sealed jar at room temperature for $2 \mathrm{~h}$, they were dipped in photographic emulsion (Ilford K2 emulsion; Ilford Ltd., Essex, UK) diluted in 2\% glycerol solution, air-dried, and exposed at $4^{\circ} \mathrm{C}$ for $7 \mathrm{~d}$.

In vitro tissue culture. The metanephros, ureter, and bladder were dissected as a unit from embryos at E14.5. The ureter was isolated from the metanephros at the level of the first branch of the ureteric bud, and the bladder was cut into halves. The left and the right ureter from each embryo were on filter discs with or without $10^{-6} \mathrm{M}$ Ang II. In a pilot study, this angiotensin dose was found to achieve a tissue Ang II level of $968 \pm 217 \mathrm{pg} / \mathrm{g}$ tissue $(n=3)$, a level similar to that found in renal tissues in vivo from newborn mice (see Results). The ureters were then incubated, using a modification of the protocol described previously for metanephric culture (9). The medium consisted of equal volumes of DME and Ham's F-12 medium supplemented with penicillin $(50 \mathrm{U} / \mathrm{ml})$, streptomycin $(50 \mu \mathrm{g} / \mathrm{ml})$, and ITS (insulin $0.01 \mathrm{mg} / \mathrm{ml}$, transferrin $0.0055 \mathrm{mg} / \mathrm{ml}$, and selenite $0.67 \mu \mathrm{g} / \mathrm{ml}$ ).

Immunostaining for $\alpha$-smooth muscle actin. The sections were stained for $\alpha$-smooth muscle actin ( $\alpha$-SMA), with an anti-human $\alpha$-SMA antibody (DAKO, Carpinteria, CA), following the manufacturer's protocol.

Ang II assays in vivo and in vitro. Ang II level was determined in kidneys from wild-type pups, metanephroi from wild-type embryos, and in vitro explants after Ang II treatment. For Ang II levels in kidneys from wild-type pups, after killing by decapitation, the kidneys were removed, cleaned of accompanying connective tissues in icecold PBS containing Bestatin (angiotensinase inhibitor; ALPCO, Windham, NH), and immediately homogenized with a Polytron (Brinkman Instruments, Inc., Westbury, NY) in $5 \mathrm{ml}$ of ice-cold $0.18 \mathrm{M}$ $\mathrm{HCl} /$ ethanol (1:3 vol/vol). For Ang II levels in metanephroi from wild-type embryos, metanephroi were dissected from E14.5 embryos in PBS containing Bestatin. At least 12 metanephroi were collected in one tube and homogenized. For Ang II levels in in vitro explants, explants were removed from the filter of culture assembly and washed briefly in an ice-cold PBS containing Bestatin twice. At least 12 explants were collected in one tube and homogenized. The homogenate was processed and Ang II was partially purified by the method of De Silva et al. (10), using extraction column packed with phenylsilylsilica (ALPCO). After evaporation to dryness, Ang II was measured by a radioimmunoassay using a commercial kit (ALPCO), following the manufacturer's protocol.

Statistical analysis. Data are presented as means \pm SE. Statistical analysis was performed using unpaired $t$ test. Differences were considered statistically significant at $P<0.05$.

\section{Results}

Our study began with the gross anatomical inspection of the kidneys of mature mice homozygous for null mutations in both the angiotensin type $1 \mathrm{~A}$ and $1 \mathrm{~B}$ receptor genes (Agtr1 -/-) (4). Unlike other mammalian species, rodents carry duplicated type 1 receptor genes, Agtrla and Agtrlb (11), necessitating the inactivation of both of them in order to study the effect of the complete absence of the type 1 receptor, AT1. The kidneys of null mutants were uniformly characterized by progressive widening of the calyx and atrophy of papilla and medulla, resulting in morphological changes characteristic of obstructive injury (Fig. 1, $A-F$ ) (4). Indeed, in these mutant mice severe tubular cell apoptosis manifests in the medulla, in a manner identical to that in the kidney of wild-type mice in which the ureter has been experimentally ligated (Fig. 1, $G-I$ ).

To understand the cause of this postnatal renal parenchymal damage, we followed the growth of the urinary tract from birth. Fig. 2, A-I, depicts the macroscopic structure of the upper urinary tract on day 0 , and at 2 and 4 wk of age. To delineate the shape of the urinary tract clearly, the outer adventitial layer is removed to expose the muscular layers. On the day of birth, there is no difference between wild-type and mutant urinary tracts. By 2 and $4 \mathrm{wk}$, the formation of the triangular pelvis is distinctively visible in the wild-type mouse. However, the morphology of the upper urinary tract is markedly distorted in Agtr1 -/- mutants. The ampulla-shaped pelvis is completely absent also in mice null mutant for the angiotensinogen gene $(A g t-/-)$ (5), where angiotensinogen is the precursor substrate for angiotensin. By contrast, there is no structural obstruction along the ureter in Agtr $1-/-$ and $A g t-/-$ mutant mice.

To elucidate the mode of induction of the pelvis by angiotensin, 5-d-old wild-type and Agtr1 -/- mice were injected with BrdU, and sections of the pelvis were immunostained with BrdU antibody. The root of the pelvis at the renal hilum is shown in Fig. 2, $J-M$. In wild-type mice, BrdU-positive nuclei are observed in great abundance in the smooth muscle layer (identified by $\alpha$-SMA staining in an adjacent section), indicating that smooth muscle cells in this area are highly proliferating. In Agtr1 -/- pups at the same age, however, there are few BrdU-positive nuclei in the smooth muscle layer along the pelvis. Quantitation of the number of BrdU-positive nuclei in both mutant and wild-type mice revealed that the percentage of BrdU-positive nuclei to total nuclei is much lower in the mutants than in the wild-type mice $(A g \operatorname{tr} 1+/+, 15.8 \pm 0.8 \%, n=$ 5 ; Agtr1 -/-, 8.3 $\pm 0.8 \%, n=5$; mean \pm SE, $P<0.001)$. By contrast, there is no appreciable difference in the BrdU labeling index in the renal parenchyma between Agtr1 +/+ and Agtr1 $-/-$ mice at P5 (in the cortex, Agtr1 +/+, 156.2 $\pm 13.2 /$ at a magnification of 400; Agtr1 -/-, 171.3 \pm 16.2 /at a magnification of $400, n=5$ : in the medulla, Agtr1 $+/+, 86.2 \pm 7.2 /$ at a magnification of 400; Agtr1 -/-, 92.3 $\pm 10.2 /$ at a magnification of $400, n=5$ ).

The growth stimulatory effects of angiotensin on the kidney outflow tract are already discernible microscopically in the ureter before the time of birth and the formation of the pelvis. Although not shown, histological examination reveals no differences at E14.5 between the ureters of wild-type embryos and embryos homozygous for null mutations in both angiotensin type $1 \mathrm{~A}$ and type $1 \mathrm{~B}$ receptor genes (Agtr1 -/-). In the newborn double mutant, however, the smooth muscle layer is significantly thinner at the proximal end compared with the wild-type mouse (Fig. 3). To quantitate the development of the smooth muscle layer at the proximal end and in the middle portion of the ureter, the thickness of the $\alpha$-SMA expressing cell layer was measured in both mutant and wild-type pups. 

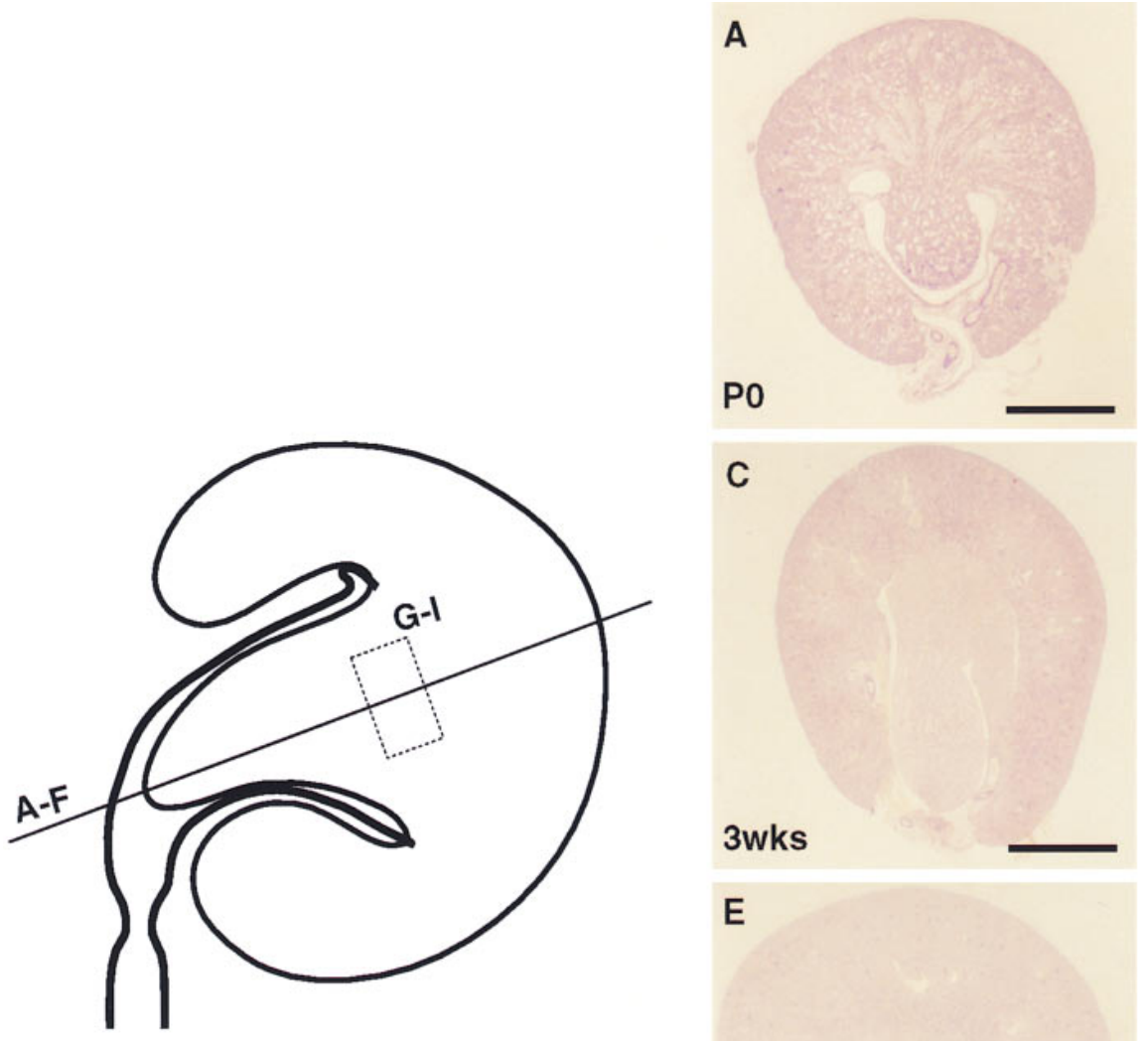

C

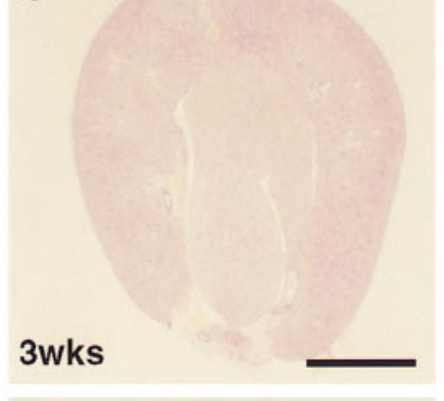

E

5wks

Agtr1 +/+

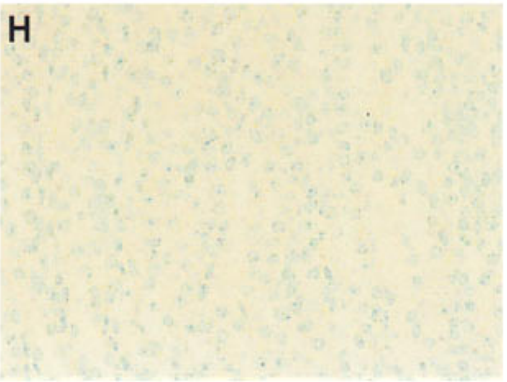

Agtr1 +/+

(Ureter ligated)

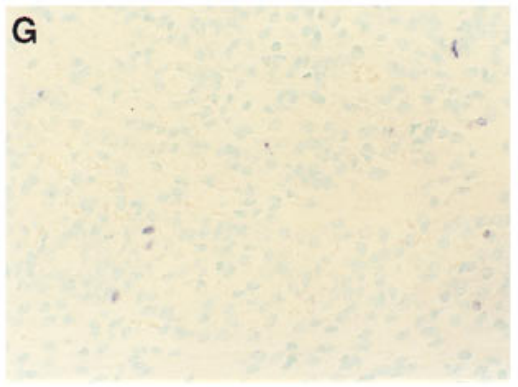

B

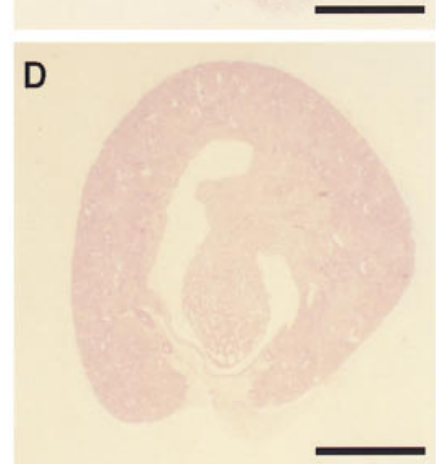

$\mathbf{F}$

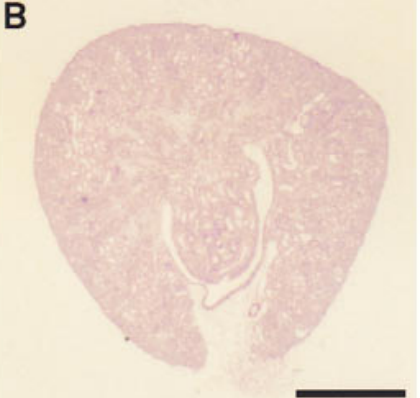

\section{I}

\section{。}

Agtr1 -/-

Figure 1. Kidney morphology of wild-type and Agtr1a/Agtr1b double null mutant mice $($ Agtr1 -/-) at different times after birth. Coronal sections of kidneys were taken as shown schematically. At birth, no gross abnormality was observed in the kidneys of Agtr $1-/-$ mice compared with wild-type mice $(A$ and $B)$. At 3 and $5 \mathrm{wk}(C-F) A g t r 1-/-$ mice showed progressive change in the papilla and calyx. Agtr1 $-/-$ mice have a hypoplastic papilla and a thin medulla, with a widening caliceal space ( $D$ and $F$ ). Scale bars, $A$ and $B, 0.4 \mathrm{~mm} ; C$ and $D, 0.8 \mathrm{~mm}$; and $E$ and $F, 2.0$ $\mathrm{mm}$. $(G$ and $H$ ) Wild-type mice at the age of $16 \mathrm{~d}$ underwent either unilateral ureteral obstruction or sham operation and were killed $5 \mathrm{~d}$ later. $(I)$ Agtr1 -/ - mice at $16 \mathrm{~d}$ were subjected to sham operation and killed 5 d later. $(G)$ Kidney section from the obstructed kidney in the wild-type mouse. Apoptotic cells are observed in the region similar to that of Agtr1-/- mice. (H) Wild-type kidney section from sham operation.

TUNEL-positive cells are virtually absent. (I) Kidney section from Agtr1 -/- mice. TUNEL-positive cells are observed in abundance, predominantly in the tubules within the medulla. 

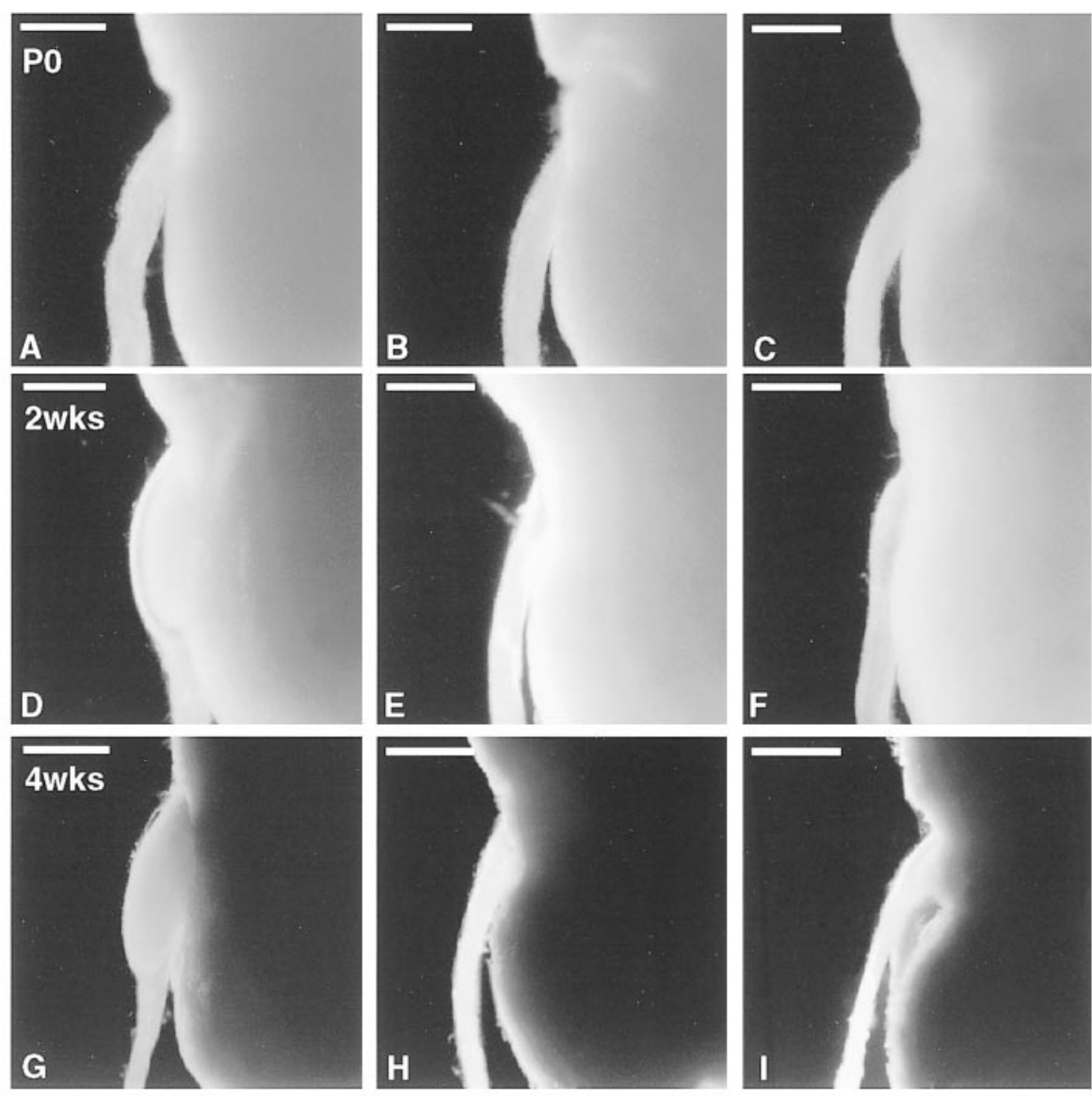

Agtr1 +/+

Agtr1 \%

Agt - -
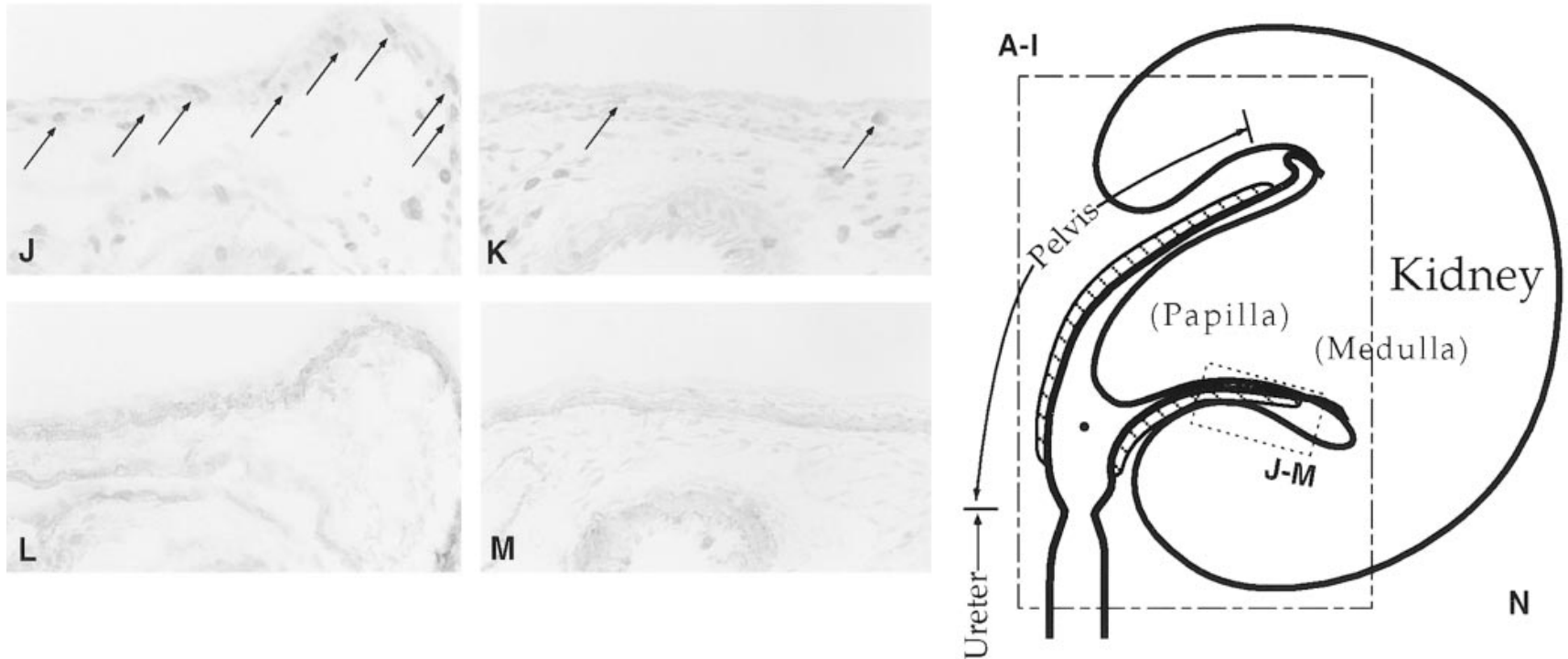

Figure 2. Pelvis morphology and smooth muscle proliferation in wild-type $($ Agtr1 $+/+)$ and Agtr1a/Agtr1b double null mutant mice $($ Agtr1 -/-). $(A-C)$ No appreciable difference was observed in pelvis morphology on the day of birth. At $2(D-F)$ and 4 wk $(G-I)$, the formation of the triangular pelvis was virtually absent in Agtr $1-/-$ and angiotensinogen null mutant mice $(A g t-/-)$. The length of the bars represents $0.3 \mathrm{~mm}$ at day $0(A-C), 0.5 \mathrm{~mm}(D-F)$ at $2 \mathrm{wk}$, and $1.0 \mathrm{~mm}$ at $4 \mathrm{wk}(G-I) . J$ and $L$ are from a Agtr $1+/+$ mouse; $K$ and $M$ are from a Agtr $1-/-$ mouse. Arrows in $J$ and $K$ indicate BrdU-positive nuclei in the smooth muscle layer. The adjacent sections are immunostained for $\alpha$-SMA to identify smooth muscle cells in $L$ and $M$. The cartoon $(N)$ shows the section sites and planes for $A-M$. The dot within the pelvic space in $N$ indicates the site where the pressure shown in Fig. 6 is monitored. 
Figure 3. Smooth muscle along the urinary tract in wild-type $($ Agtr1 +/+) and Agtr1a/Agtr1b double null mutant mice (Agtr1 $-/-)$ at birth. Transverse sections of the cranial-most portion of the ureter immunostained for $\alpha$-SMA. There are significantly fewer smooth muscle cells in

\section{Agtr1+/+}

This analysis showed a $53 \%$ reduction in wall thickness proximally ( $79 \pm 5 \mu \mathrm{m}$ in Agtr1 $+/+, n=6$ vs. $37 \pm 3 \mu \mathrm{m}$ in Agtr1 -/-, $n=6$, mean \pm SE, $P<0.001)$ and $17 \%$ distally $(77 \pm 2 \mu \mathrm{m}$ in Agtrl $+/+, n=6$ vs. $64 \pm 3 \mu \mathrm{m}$ in Agtrl $-/-, n=6$, mean \pm SE, $P<0.001)$. Thus, the embryonic development of ureteral smooth muscle cells is markedly attenuated in Agtr1 -/- embryos.

Several lines of evidence suggest that smooth muscle differentiation along the ureter in the wild-type mouse reflects a direct local action of angiotensin on the tissues. First, the existence of angiotensin type 1 receptors, AT1, along the upper urinary tract was established, using receptor autoradiography with ${ }^{125}$ I-labeled $\left[\mathrm{Sar}^{1}\right.$,Ile $\left.{ }^{8}\right]$ Ang II as a ligand, together with excess PD 123319 as a competitor for the angiotensin type 2 receptor. As shown in Fig. 4, $A$ and $D$, angiotensin binding sites at the renal hilum are already induced at birth in the wild-type newborn, and further intensified in the smooth muscle cell layer of the renal pelvis over the next $4 \mathrm{wk}$. By contrast, Ang II binding is virtually undetectable in the medulla, the papilla, and vascular smooth muscles of the large and small renal arteries. Binding of the radiolabeled ligand was significantly reduced by the simultaneous addition of an excess amount of losartan (Fig. 4, $C$ and $F$ ), and the binding was absent in Agtr1 $-/-$ mice (Fig. 4, $B$ and $E$ ). Second, Ang II content was measured in metanephroi from embryos at E14.5, E15.5, and E17.0 and in kidneys from mice at birth, 1,3 , and 8 wk (Fig. $4 H$ ). In metanephroi from embryos at E14.5 and E15.5, Ang II levels average $110 \pm 12 \mathrm{pg} / \mathrm{g}$ tissue $(n=3)$, and $100 \pm 25 \mathrm{pg} / \mathrm{g}$ tissue $(n=3)$, respectively. Ang II levels increase nearly eightfold in metanephroi at E17.0, reach a peak on the day of birth at a level of $975 \pm 136 \mathrm{pg} / \mathrm{g}$ tissue $(n=6)$, and decrease subsequently. Thus, both high concentration of ligand in the kidney and localized expression of the receptor underlie the selective growth stimulatory effect of Ang II on the renal pelvic smooth muscle.

To directly test the capacity of Ang II to induce ureteral smooth muscle, a ureteric organ culture system was established in which the ureter was harvested from E14.5 embryos and cultured for $1 \mathrm{~d}$ with or without $10^{-6} \mathrm{M}$ Ang II. As mentioned above, undifferentiated mesenchymal cells along the

\section{Agtr1 -/-} Agtr1 -/- (b) compared with wild-type mice $(a)$ at birth.

ureter do not express $\alpha$-SMA in either wild-type or mutant embryos at E14.5. In wild-type specimens, Ang II caused a significant increase in the percentage of $\alpha$-SMA positive cells (Fig. 5 C), on average from $6.21 \pm 0.80 \%$ to $13.20 \pm 2.39 \%$ (Fig. $5 E, n=5$; mean \pm SE, $P<0.001)$. By contrast, in Agtr 1 null mutant mice, Ang II treatment had no effect on the expression of $\alpha$-SMA (Fig. $5 \mathrm{D}$ ) (control, $1.80 \pm 0.59 \%, n=5$; Ang II, $1.90 \pm 0.52 \%, n=5$; mean \pm SE) (Fig. $5 E$ ). Thus, Ang II has a local regulatory capacity on the differentiation and/or proliferation of smooth muscle along the ureter.

The renal pelvis eliminates urine from the calyx by generating pressure, directed only forward by constant unidirectional peristaltic movement initiated by the pacemaker cells within the pelvis, allowing removal of urine from the calyx without generating backward pressure to the renal parenchyma $(2,3)$. To assess the function of the renal pelvis in the mutant, intrapelvic pressure was monitored by the micropuncture servonulling method (6). The tracing pattern of pelvic pressure is shown in Fig. 6. In all of the 4- to 5-wk-old wild-type mice examined $(n=4)$, the renal pelvic pressure exhibits rhythmic pulsatile changes with constant frequency. In mutant mice $(n=4)$, however, the regular contraction of the renal pelvis is absent and the baseline of intrapelvic pressure is higher than that in the wild-type mouse (Agtr1 +/+, 5.2 $1.8 \mathrm{mmHg}$; Agtr1 $-/-, 12.5 \pm 1.8 \mathrm{mmHg}$, mean $\pm \mathrm{SE}, P<0.01)$, whereas urine flow rate is similar (Agtr1 +/+, $86 \mu \mathrm{l} / \mathrm{h} ;$ Agtr1 -/-, $92 \mu \mathrm{l} / \mathrm{h})$. Note that the renal parenchyma of mutant mice is now directly and constantly exposed to the abnormally high pressure in the absence of the pelvis, which normally isolates the renal parenchyma from the downstream pressure.

\section{Discussion}

Agtr1 -/ - mice lack development of the renal pelvis, and the smooth muscle layer develops poorly throughout the length of the ureter. Most remarkably, the pelvis is entirely missing in Agtr1 -/- mice. This anomalous development reflects a lack of local tissue effect of angiotensin. Thus, angiotensin type 1 receptor in the wild-type mouse is highly localized within the pelvic wall but absent in the medulla (Fig. 4) $(4,12)$. Moreover, 

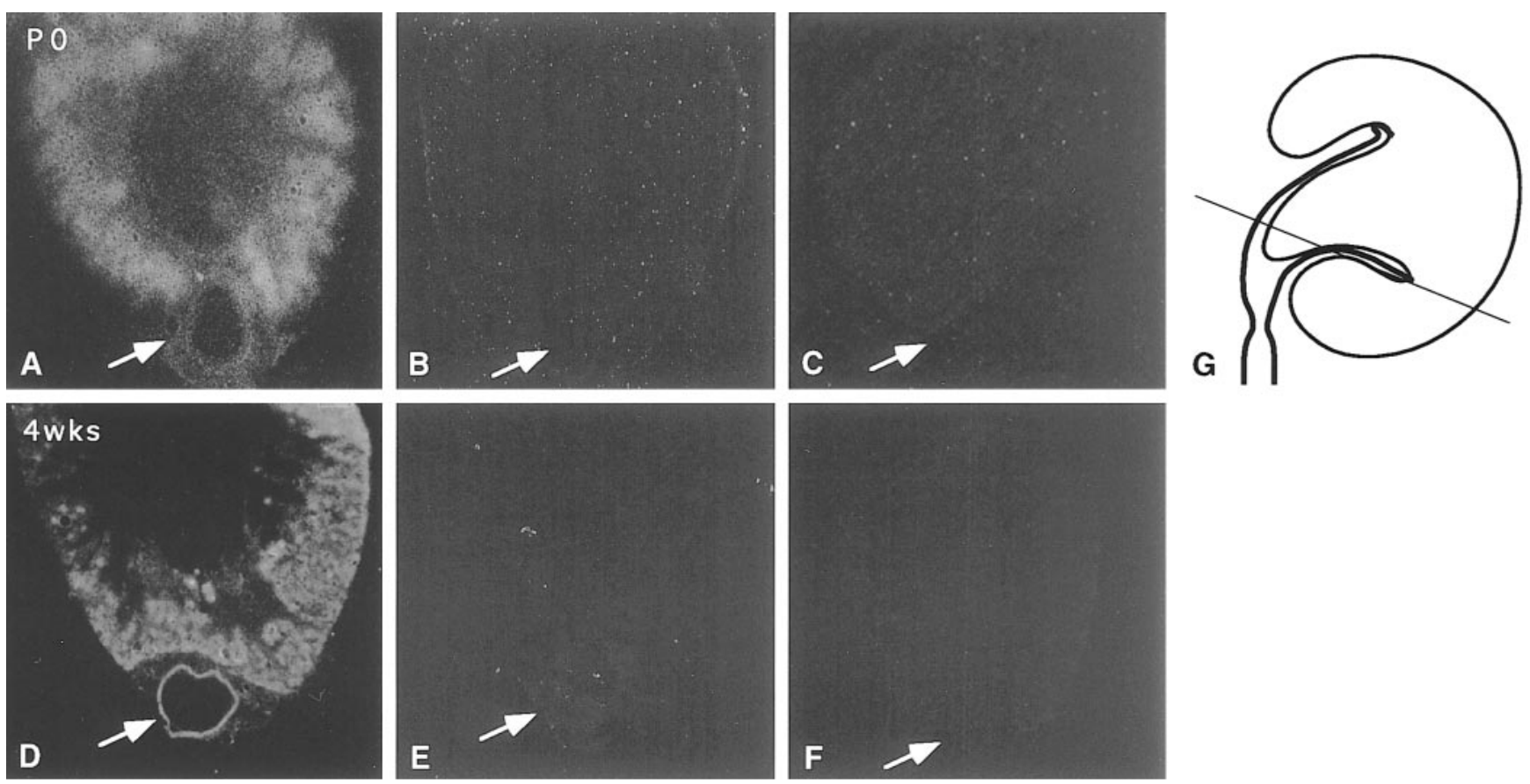

Agtr1 +/+

Agtr1 \%-

Agtr1 +/+

(+losartan)

H

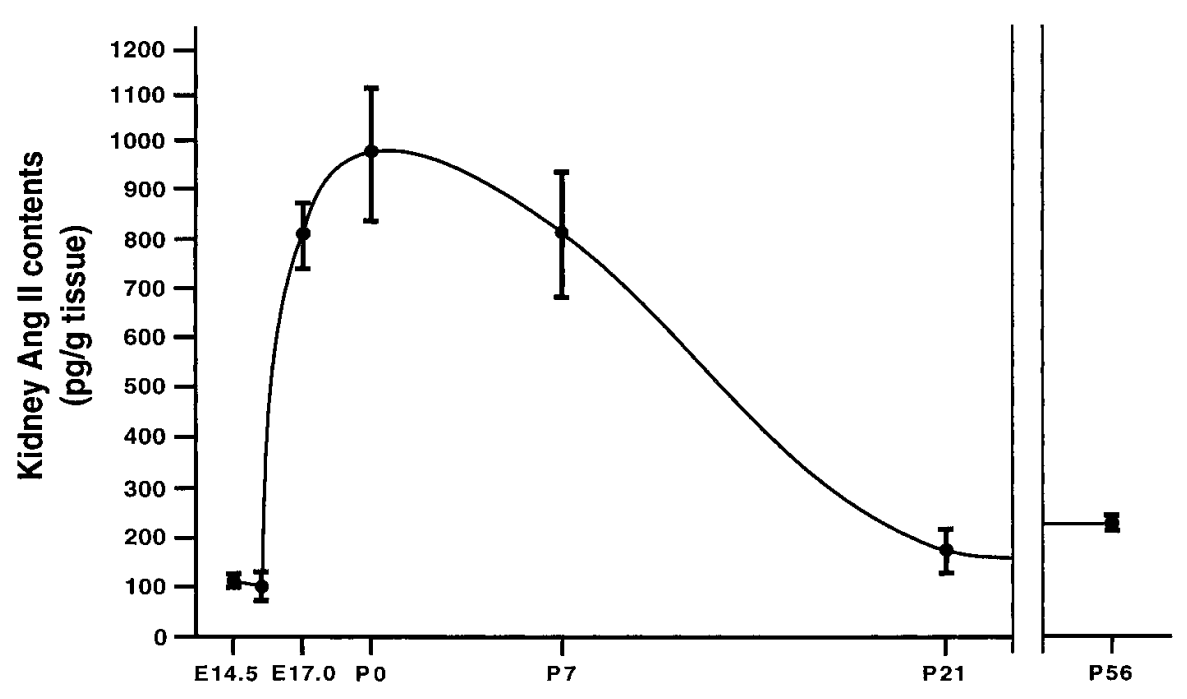

Figure 4. Distribution of Ang II receptors in the pelvis in wild-type $($ Agtr1 $+/+)$ and Agtr1a/Agtr1b double null mutant mice (Agtr1 -/-) and renal Ang II content in wild-type mice. ${ }^{125}$ I-labeled $\left[\mathrm{Sar}^{1}, \mathrm{Ile}^{8}\right]$ Ang II was used as a ligand together with excess PD 123319 as a competitor for angiotensin type 2 receptors. ( $A$ ) Ang II binding sites at the hilum, as well as the renal cortex, are already induced at birth. $(D)$ At 4 wk after birth, a high concentration of binding sites is observed in the smooth muscle cell layer of the renal pelvis, in the cortical areas, and around the glomeruli, whereas Ang II binding is extremely low in the medulla. ( $B$ and $E$ ) Binding was virtually absent in Agtr1 - $/-$ mice. ( $C$ and $F$ ) Binding was significantly reduced by the simultaneous addition of an excess amount of losartan. Arrows in $A-F$ indicate the kidney hilum. The cartoon $(G)$ shows the section site and plane. $(H)$ Ang II contents in the meta-

nephros and kidney. Values are presented as means \pm SE at E14.5 $(n=3), \mathrm{E} 15.5(n=3), \mathrm{E} 17.0(n=4), \mathrm{P} 0(n=6), \mathrm{P} 7(n=4), \mathrm{P} 21(n=4)$, and P56 $(n=4)$. Ang II level was elevated markedly and transiently around birth.

the experimental manipulation to raise angiotensin concentration within the embryonic ureteric tissue explant of the wildtype to a level comparable to that prevailing in the neonatal tissue in vivo led to induction of ureteral smooth muscles when AT1 receptors are present. Of note, the pressure within the pelvic lumen, which can potentially act as a trophic stimulus for the smooth muscle $(13,14)$, is higher in the Agtr1 -/- than wild-type mice (Fig. 6). These findings are reminiscent of the suggestion that angiotensin acts as a growth factor on vascular smooth muscle cells (15-17) and cardiomyocytes $(18,19)$. While studies on gene targeted mice selectively deficient of
Ang II $(5,20-23)$ or its receptors (24-27) have heretofore been unsuccessful in demonstrating the significance of such a growth factor-like action in the development of these organs, this study has provided in vitro and in vivo evidence documenting the ontogenic importance of Ang II on the ureteral smooth muscle growth.

The pelvis, due to its pacemaker function and contractility, allows sequestration of urine from the calyx without generating backward pressure to the renal parenchyma $(2,3)$. Indeed, monitoring of intrapelvic pressure in wild-type mice demonstrated typical steady cyclic pressure changes whereas such a 


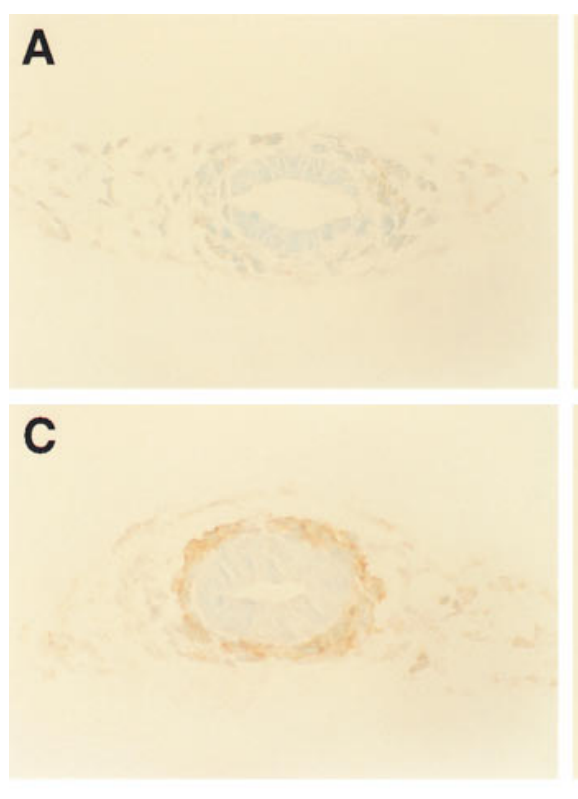

Agtr1 +/+

E

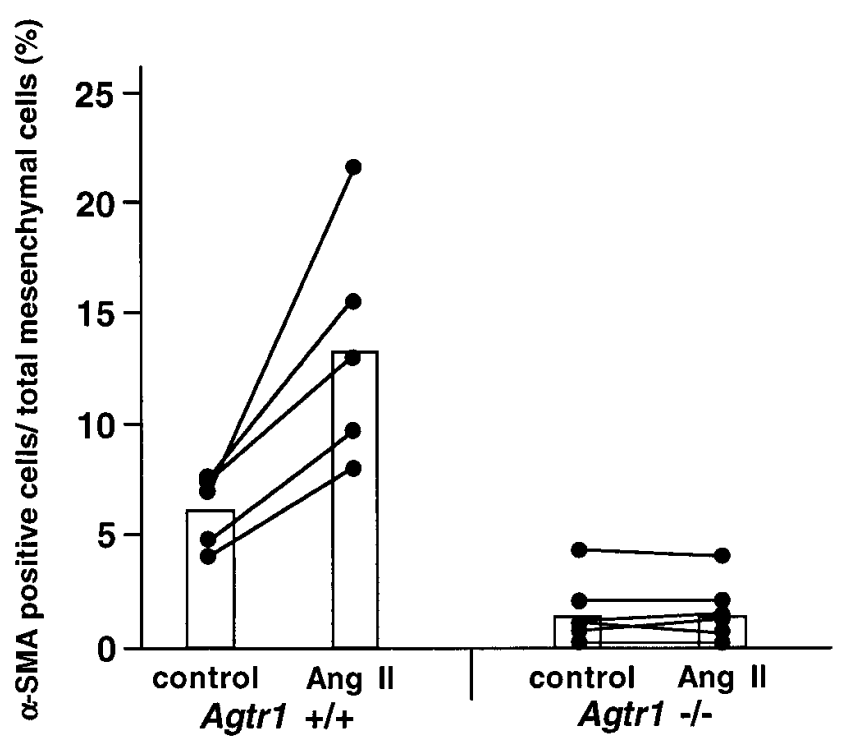

rhythmic movement was entirely lacking, and instead, constant abnormally elevated intrapelvic pressure characterizes Agtrl -I- mice (Fig. 6). This elevated pressure is considered particularly injurious to the renal parenchyma when the peristaltic movement from the hilum and downward is absent, as no other mechanism isolates the renal parenchyma from this high downstream pressure. Not surprisingly, therefore, the medulla and papilla, which appear intact at birth, become atrophic within a few weeks after birth in the kidneys of Agtr1 -/- mice.

Indeed, morphometrically, immunohistochemically and otherwise, the nature of this injury in Agtr1 -/- kidneys is qualitatively indistinguishable from that in wild-type kidneys that have been subjected to a complete surgical ureteral ligation. Thus, in both the mutant and artificially obstructed kidneys, the calyx is enlarged, while the papilla is atrophic (Fig. $1 F$ ); tubulointerstitial cells are not only abnormally apoptotic (Fig. 1,
Figure 5. In vitro effect of Ang II to induce smooth muscle cells in ureteral tissues from wild-type $(A g \operatorname{tr} 1+/+)$ and $A g \operatorname{tr} 1 a / A g t r 1 b$ double null mutant embryos (Agtr1 -/-). Embryonic ureter harvested from Agtr1 $+/+$ or $A g t r 1-/-$ embryos at E14.5 was cultured for $1 \mathrm{~d}$ in the presence $(C$ and $D)$ or absence ( $A$ and $B$ ) of $10^{-6} \mathrm{M}$ Ang II. The explant was then fixed with $4 \%$ PFA, routinely processed, embedded upright in paraffin, and the ureter was serially sectioned at $4 \mu \mathrm{m}$. At least 10 transverse sections were chosen evenly throughout the length of ureter, and each section was stained with $\alpha$-SMA antibody. $(A-D)$ Transverse section at the same level stained for $\alpha$-SMA. $(E)$ The density of $\alpha$-SMA expressing cells was determined as a percentage of the $\alpha$-SMA-positive cells against total mesenchymal cells surrounding the ureteral epithelium along the ureter. In tissues from wild-type embryos, Ang II caused a significant $(P<0.001)$ increase in the percentage of $\alpha$-SMA-positive cells. By contrast, in tissues from Agtr1 null mutant embryos, Ang II treatment had no effect on the percentage of $\alpha$-SMA-positive cells. Control and Ang II treatments are paired as the tissues are from the same embryos. Mean values are given by open bars.

$G$ and $I$ ) but are also proliferative (28). Both are also characterized by interstitial macrophage infiltration and fibrosis, and within the local fibrotic area, TGF- $\beta 1$, PDGF-A, and IGF-1 are upregulated, whereas EGF is downregulated as determined at both mRNA and protein levels (28). A similar abnormal morphology of the kidneys has been reported in mice homozygous for null mutations in genes that are required for angiotensin production, namely the angiotensinogen $(A g t)(5$, $20)$ or angiotensin converting enzyme (Ace) genes (21-23). Of interest, the morphological anomalies (Fig. 1, $A-F$ ) and increased apoptotic activity of Agtr1 -/- mice develop not before birth (data not shown) but only after $2 \mathrm{wk}$ of age. This highly developmental stage-specific kidney-injurious effect of AT1 inhibition has been shown pharmacologically in rats given AT1 antagonist (29). The latter is reminiscent of the reports that, in humans, administration of ACE inhibitor during 


\section{$\mathrm{mmHg}$}

Figure 6. Renal pelvic peristalsis in wildtype $(A g t r 1+/+)$ and Agtrla/Agtr1b double null mutant mice (Agtr1 -/-). Intrapelvic pressure was monitored by the servonulling micropuncture method. In all of the wild-type mice examined, the renal pelvic pressure exhibits rhythmic and constant pulsatile contraction. In the mutant mice, however, the normal pulsative pattern is absent. Atmospheric pressure is presented on the right side of the trace as 0 $\mathrm{mmHg}$. The site where pressure was monitored is indicated by the dot within the pelvic space illustrated in Fig. $2 \mathrm{~N}$. the third trimester of pregnancy was associated with "ACE inhibitor fetopathy," which includes kidney anomalies (30-32). Although available histological data are sparse in the literature, the pathology appears to include renal dysplasia, a pattern that has been shown to occur in experimental ureteral ligation in a late stage of nephrogenesis (33). The pattern of hydronephrosis seen in mice during angiotensin inhibition, pharmacologically or genetically, has not been documented, however. Given the notion that, in many aspects, the renal function and structure of neonatal rodents resemble those of human embryos at the third trimester, the possibility is raised that the renal anomaly of ACE inhibitor fetopathy is, in part, related to the defective development of urinary peristalsis. Incidentally, in humans, a drastic increase in urine flow rate occurs during the third trimester (34), and the renal pelvis develops during this period as well (35), along with an upregulation of renal angiotensin (36).

The results of this study impart physiological significance to two well-known, yet heretofore teleologically puzzling phenomena in the renin-angiotensin system. The first relates to the onset of extrauterine life as the timing of angiotensin upregulation. The renin-angiotensin system is transiently upregulated during the perinatal period $(36,37)$, the significance of which has long been debated (38), as pharmacological inhibition has little effect as far as acute hemodynamic changes are concerned. In view of the dramatic increase in urine flow during the perinatal period, the angiotensin upregulation appears very timely so that the pelvis can be induced promptly to accommodate this physiological stress unique to mammals. The second relates to the kidney as the primary regulatory organ for the renin-angiotensin system. The kidney, through its ability to regulate the renin-angiotensin system, plays a major role in the homeostasis of systemic circulatory dynamics. In this context, the present observation that a local upregulation of angiotensin is involved in the induction of the renal pelvis provides us with the teleological justification that the kidney can be considered as the ideal site to harbor the renin-angiotensin regulator. If the kidney is indeed the origin of the angiotensin that acts on the downstream smooth muscles, the renally derived angiotensin allows both of these homeostatic mechanisms to operate, i.e., the systemic circulatory dynamics and the dynamics of urinary outflow, under the direct influence of the renal renin-angiotensin system.

\section{Acknowledgments}

This work was supported by National Institutes of Health grants DK44757 and DK-37868. Dr. Brigid L.M. Hogan is an Investigator of the Howard Hughes Medical Institute. Dr. Agnes Fogo is a recipient of an Established Investigator Award from the American Heart Association.

\section{References}

1. Boylan, B.Y.J.W., E.P. Colbourn, and R.A. McCance. 1958. Renal function in the foetal and new-born guinea-pig. J. Physiol. 141:323-331.

2. Constantinou, C.E. 1974. Renal pelvic pacemaker control of peristaltic rate. Am. J. Physiol. 226:1413-1419.

3. Constantinou, C.E., and J.R. Hrynczuk. 1976. Urodynamics of the upper urinary tract. Invest. Urol. 14:233-240.

4. Tsuchida, S., T. Matsuzaka, X. Chen, S. Okubo, F. Niimura, H. Nishimura, A. Fogo, H. Utsunomiya, T. Inagami, and I. Ichikawa. 1998. Murine double nullizygotes of the angiotensin type $1 \mathrm{~A}$ and $1 \mathrm{~B}$ receptor genes have all the major abnormal phenotypes of angiotensinogen nullizygotes. J. Clin. Invest. 101:755-760.

5. Niimura, F., P.A. Labosky, J. Kakuchi, S. Okubo, H. Yoshida, T. Oikawa, T. Ichiki, A.J. Naftilan, A. Fogo, T. Inagami, et al. 1995. Gene targeting in mice reveals a requirement for angiotensin in the development and maintenance of kidney morphology and growth factor regulation. J. Clin. Invest. 96:2947-2954.

6. Yoshida, Y., A. Fogo, and I. Ichikawa. 1989. Glomerular hemodynamic changes vs. hypertrophy in experimental glomerular sclerosis. Kidney Int. 35: 654-660.

7. Gavrieli, Y., Y. Sherman, and S.A. Ben-Sasson. 1992. Identification of programmed cell death in situ via specific labeling of nuclear DNA fragmentation. J. Cell Biol. 119:493-501.

8. Ciuffo, G.M., M. Viswanathan, A.M. Seltzer, K. Tsutsumi, and J.M. Saavedra. 1993. Glomerular angiotensin II receptor subtypes during development of rat kidney. Am. J. Physiol. 265:F264-F271.

9. Avner, E.D., W.E. Sweeney, Jr., N.P. Piesco, and D. Ellis. 1985. Growth factor requirements of organogenesis in serum-free metanephric organ culture. In Vitro Cell. Dev. Biol. 21:297-304.

10. De Silva, P.E., A. Husain, R.R. Smeby, and P.A. Khairallah. 1988. Measurement of immunoreactive angiotensin peptides in rat tissues: some pitfalls of angiotensin II analysis. Anal. Biochem. 174:80-87.

11. Yoshida, H., J. Kakuchi, D.F. Guo, H. Furuta, N. Iwai, R. van der Meerde Jong, T. Inagami, and I. Ichikawa. 1992. Analysis of the evolution of angiotensin II type 1 receptor gene in mammals (mouse, rat, bovine and human) Biophys. Biochem. Res. Commun. 186:1042-1049.

12. Gasc, J.-M., S. Shanmugam, M. Sibony, and P. Corvol. 1994. Tissue-specific expression of type 1 angiotensin II receptor subtypes: an in situ hybridization study. Hypertension. 24:531-537.

13. Starr, N.T., M. Maizels, P. Chou, R. Brannigan, and E. Shapiro. 1992. Microanatomy and morphology of the hydronephrotic obstructed renal pelvis in asymptomatic infants. J. Urol. 148:519-524.

14. Cheng, E.Y., M. Maizels, P. Chou, V. Hartanto, and E. Shapiro. 1993. Response of the newborn ureteropelvic junction complex to induced and later reversed partial ureteral obstruction in the rabbit model. J. Urol. 150:782-789.

15. Campbell-Boswell, M., and A.L. Robertson, Jr. 1981. Effects of angio- 
tensin II and vasopressin on human smooth muscle cells in vitro. Exp. Mol. Pathol. 35:265-276.

16. Turla, M.B., M.M. Thompson, M.H. Corjay, and G.K. Owens. 1991. Mechanisms of angiotensin II- and arginine vasopressin-induced increases in protein synthesis and content in cultured rat aortic smooth muscle cells. Evidence for selective increases in smooth muscle isoactin expression. Circ. Res. 68:288-299.

17. Gibbons, G.H., R. Pratt, and V.J. Dzau. 1992. Vascular smooth muscle cell hypertrophy vs. hyperplasia. Autocrine transforming growth factor-beta expression determines growth response to angiotensin II. J. Clin. Invest. 90:456461.

18. Baker, K.M., and J.M. Aceto. 1990. Angiotensin II stimulation of protein synthesis and cell growth in chick heart cells. Am. J. Physiol. 259:H610H618.

19. Sadoshima, J., and S. Izumo. 1993. Molecular characterization of angiotensin II-induced hypertrophy of cardiac myocytes and hyperplasia of cardiac fibroblasts: critical role of the AT1 receptor subtype. Circ. Res. 73:413-423.

20. Nagata, M., K. Tanimoto, A. Fukamizu, Y. Kon, F. Sugiyama, K. Yagami, K. Murakami, and T. Watanabe. 1996. Nephrogenesis and renovascular development in angiotensinogen-deficient mice. Lab. Invest. 75:745-753.

21. Krege, J.H., S.W.M. John, L.L. Langenbach, J.B. Hodgin, J.R. Hagaman, E.S. Bachman, J.C. Jennette, D.A. O'Brien, and O. Smithies. 1995. Malefemale differences in fertility and blood pressure in ACE-deficient mice. $\mathrm{Na}$ ture. 375:146-148.

22. Carpenter, C., A.A. Honkanen, H. Mashimo, K.A. Goss, P. Huang, M.C. Fishman, M. Asaad, C.R. Dorso, and H.-S. Cheung. 1996. Renal abnormalities in mutant mice. Nature. 380:292.

23. Esther, C.R., Jr., T.E. Howard, E.M. Marino, J.M. Goddard, M.R. Capecchi, and K.E. Bernstein. 1996. Mice lacking angiotensin-converting enzyme have low blood pressure, renal pathology, and reduced male fertility. Lab. Invest. 74:953-965.

24. Ito, M., M.I. Oliverio, P.J. Mannon, C.F. Best, N. Maeda, O. Smithies, and T.M. Coffman. 1995. Regulation of blood pressure by the type 1A angiotensin II receptor gene. Proc. Natl. Acad. Sci. USA. 92:3521-3525.

25. Sugaya, T., S. Nishimura, K. Tanimoto, E. Tanimoto, T. Yamaguchi, K. Imamura, S. Goto, K. Imaizumi, Y. Hisada, A. Otsuka, et al. 1995. Angiotensin II type 1a receptor deficient mice with hypotension and hyperreninemia. $J$. Biol. Chem. 270:18719-18722.

26. Matsuzaka, T., H. Nishimura, H. Utsunomiya, J. Kakuchi, F. Niimura, T. Inagami, A. Fogo, and I. Ichikawa. 1996. Chimeric mice carrying "regional" targeted deletion of the angiotensin type $1 \mathrm{~A}$ receptor gene. Evidence against the role for local angiotensin in the in vivo feedback regulation of renin synthesis in juxtaglomerular cells. J. Clin. Invest. 98:1867-1877.

27. Chen, X., W. Li, H. Yoshida, S. Tsuchida, H. Nishimura, F. Takemoto, S. Okubo, A. Fogo, T. Matsuzaka, and I. Ichikawa. 1997. Targeting deletion of angiotensin type 1B receptor gene in the mouse. Am. J. Physiol. 272:F299F304.

28. Miyazaki, Y., S. Tsuchida, H. Nishimura, R.C. Harris, J.M. McKanna, T. Inagami, A. Fogo, and I. Ichikawa. 1998. Angiotensin induces the urinary tract peristaltic machinery immediately after birth. J. Am. Soc. Nephrol. (Abstr.) In press.

29. Friberg, P., B. Sundelin, S.-O. Bohman, A. Bobik, H. Nilsson, A. Wickman, H. Gustafsson, J. Petersen, and M.A. Adams. 1994. Renin-angiotensin system in neonatal rats: induction of a renal abnormality in response to ACE inhibition or angiotensin II antagonism. Kidney Int. 45:485-492.

30. Nightingale, S.L. 1992. Warnings on the use of ACE inhibitors in second and third trimester of pregnancy. JAMA (J. Am. Med. Assoc.). 267:2445.

31. Pryde, P.G., A.B. Sedman, C.E. Nugent, and M. Barr, Jr. 1993. Angiotensin-converting enzyme inhibitor fetopathy. J. Am. Soc. Nephrol. 3:15751582.

32. Sedman, A.B., D.B. Kershaw, and T.E. Bunchman. 1995. Recognition and management of angiotensin converting enzyme inhibitor fetopathy. Pediatr. Nephrol. 9:382-385.

33. Peters, C.A., M.C. Carr, A. Lais, A.B. Retik, and J. Mandell. 1992. The response of the fetal kidney to obstruction. J. Urol. 148:503-509.

34. Rabinowitz, R., M.T. Peters, S. Vyas, S. Campbell, and K.H. Nicolaides. 1989. Measurement of fetal urine production in normal pregnancy by real-time ultrasonography. Am. J. Obstet. Gynecol. 161:1264-1266.

35. Itatani, H., T. Koide, A. Okuyama, S. Mizutani, and T. Sonoda. 1979. Development of the calyceal system in the human fetus. Invest. Urol. 16:388394

36. Taylor, M.G., S.W. Peart, K.A. Porter, L.H. Zondek, and T. Zondek. 1986. Concentration and molecular forms of active and inactive renin in human fetal kidney, amniotic fluid and adrenal gland: evidence for renin angiotensin system hyperactivity in 2nd trimester of pregnancy. J. Hypertens. 4:121-129.

37. Kotchen, T.A., A.L. Strickland, T.W. Rice, and B.S. Walters. 1972. A study of the renin-angiotensin system in newborn infants. J. Pediatr. 80:938946.

38. Jose, P.A., L.M. Slotkoff, S. Montgomery, P.L. Calcagno, and G. Eisner 1975. Autoregulation of renal blood flow in the puppy. Am. J. Physiol. 229:983988. 